\title{
Paper Sensors Based on Fluorescence Changes of Carbon Nanodots for Optical Detection of Nanomaterials
}

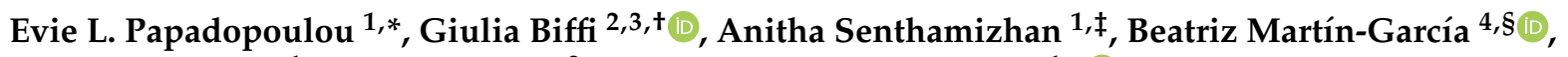 \\ Riccardo Carzino ${ }^{1}$, Roman Krahne ${ }^{2}$ and Athanassia Athanassiou ${ }^{1, *}$ \\ 1 Smart Materials Group, Istituto Italiano di Tecnologia, Via Morego 30, 16163 Genova, Italy; \\ anitha.senthamizhan@iit.it (A.S.); ricardo.carzino@iit.it (R.C.) \\ 2 Optoelectronics, Istituto Italiano di Tecnologia, Via Morego 30, 16163 Genova, Italy; giulia.biffi@iit.it (G.B.); \\ roman.krahne@iit.it (R.K.) \\ 3 Dipartimento di Chimica e Chimica Industriale, Università degli Studi di Genova, Via Dodecaneso 31, \\ 16146 Genova, Italy \\ 4 Graphene Labs, Istituto Italiano di Tecnologia, Via Morego 30, 16163 Genova, Italy; \\ b.martingarcia@nanogune.eu \\ * Correspondence: paraskevi.papadopoulou@iit.it (E.L.P.); athanassia.athanassiou@iit.it (A.A.) \\ + Current Address: Materials Physics Center (CFM), Spanish National Research Council (CSIC), \\ 20018 Donostia, Spain. \\ $\ddagger$ Current Address: Nanobiointeractions and Nanodiagnostics, Istituto Italiano di Tecnologia, Via Morego 30, \\ 16163 Genova, Italy. \\ $\S$ Current Address: CIC nanoGUNE, Tolosa Hiribidea, 76, 20018 Donostia, Spain.
}

\section{check for} updates

Citation: Papadopoulou, E.L.; Biffi, G.; Senthamizhan, A.; Martín-García, B.; Carzino, R.; Krahne, R.; Athanassiou, A. Paper Sensors Based on Fluorescence Changes of Carbon Nanodots for Optical Detection of Nanomaterials. Sustainability 2021, 13, 11896. https://doi.org/10.3390/ su132111896

Academic Editors: Irene Bellagamba and Fabio Boccuni

Received: 10 September 2021

Accepted: 22 October 2021

Published: 27 October 2021

Publisher's Note: MDPI stays neutral with regard to jurisdictional claims in published maps and institutional affiliations.

Copyright: (c) 2021 by the authors. Licensee MDPI, Basel, Switzerland. This article is an open access article distributed under the terms and conditions of the Creative Commons Attribution (CC BY) license (https:// creativecommons.org/licenses/by/ $4.0 /)$.

\begin{abstract}
A paper sensor was designed in order to detect the presence of nanomaterials, such as $\mathrm{ZnO}$ and silica nanoparticles, as well as graphene nanoplatelets $(\mathrm{GnP})$, based on fluorescence changes of carbon nanodots. Paper strips were functionalized with carbon nanodots using polyvinyl alcohol (PVA) as binder. The carbon nanodots were highly fluorescent and, hence, rendered the (cellulosic) paper stripes emissive. In the presence of silica and $\mathrm{ZnO}$ nanoparticles, the fluorescence emission of the carbon nanodots was quenched and the emission decay was shortened, whereas in the presence of GnP only emission quenching occurred. These different photoluminescence (PL) quenching mechanisms, which are evident from lifetime measurements, convey selectivity to the sensor. The change in fluorescence of the carbon dot-functionalized paper is also evident to the naked eye under illumination with a UV lamp, which enables easy detection of the nanomaterials. The sensor was able to detect the nanomaterials upon direct contact, either by dipping it in their aqueous dispersions, or by sweeping it over their powders. The use of the proposed optical sensor permits the detection of nanomaterials in a straightforward manner, opening new ways for the development of optical sensors for practical applications.
\end{abstract}

Keywords: carbon nanodots; paper sensor; optical sensor; fluorescence sensor

\section{Introduction}

The last 20 years have seen a boom in nanotechnology and in the production and use of engineered nanomaterials. Their small size and high surface-to-volume ratio has unraveled novel properties with great importance to science and technology, resulting in an enormous increase in their production. Nanomaterials find commercial applications in a wide range of fields, such as cosmetics [1], the food industry [2], and drug delivery systems [3,4]. Furthermore, they are also used in industrial processes like catalysis [5] or in the fabrication of electronics [6]. Due to the increased rate of their production and use, their potential release in the environment and risk assessment has given rise to a pertinent scientific discussion [7-9]. The first to be exposed to nanomaterials are workers in research and development [9], either in industry or in academic research. In the present work, 
we describe the development of an optical sensor for the fast detection of nanomaterials, focusing our attention on single-material production lines.

Currently, the detection of nanomaterials [10], either airborne or in colloids, involves spectroscopic techniques, like Raman spectroscopy [11], inductively coupled plasma mass spectrometry (ICP-MS) [12,13], or gravimetric detection [14]. These methods are very accurate and quantitative; however, they require multiple steps (i.e., they are time consuming), involving the collection of samples from the site of interest and their subsequent analysis in the lab, as well as a high degree of expertise.

In the present work, we describe the development of an optical sensor for the fast detection of nanomaterials. The detection is based on the photoluminescence (PL) changes of carbon dots, when they are in contact with various nanomaterials, more precisely, silica $\left(\mathrm{SiO}_{2}\right)$ and zinc oxide $(\mathrm{ZnO})$ nanoparticles $(\mathrm{NPs})$ and graphene nanoplatelets $(\mathrm{GnP})$. Silica and zinc oxide are among the most frequently used engineered nanoparticles, and they are used in cosmetics, paints, electronics, optics, etc. [7]. Furthermore, graphene is now considered as the most promising nanomaterial for technological applications, especially in electronics and optics [11]. It then becomes evident that their facile, quick detection is highly relevant.

Herein, commercial filter paper was coated with carbon dots mixed in water with polyvinyl alcohol (PVA) that acted as a binder. The functionalized paper was brought in contact with the various nanomaterials (silica NPs, ZnO NPs, and GnP), either in solution or in powder form, and the consequent changes in fluorescence were studied. Subsequently, time-resolved PL measurements revealed different PL decay behavior for the different nanomaterials, conveying selectivity to the paper sensor. We also demonstrated that detection of the aforementioned nanomaterials can take place simply by naked-eye optical inspection of the paper sensor under an ultraviolet (UV) lamp.

The fluorescence of carbon dots can be quenched in the presence of various chemical analytes, including metal ions [15-19] or organic [20,21] or inorganic molecules [22,23]. Furthermore, the fluorescence of carbon dot-based nanocomposites with carbon nanotubes [24] or inorganic nanoparticles [25-28] has been investigated with respect to the charge transfer in the carbon dot-nanomaterial interface. To the best of our knowledge, this is the first report where the application of fluorescent carbon dots has been extended for the detection of inorganic nanomaterials. The proposed sensor is ideal for the quick detection of nanomaterials, especially useful in environments where the nature of the potential contaminant is normally known, such as research laboratories and industrial production lines. In addition, the aforementioned protocols are based on solutions, making practical applications difficult. To this end, paper sensors are considered more practical for real life applications, since they are more easily handled and operated and, finally, can be incorporated in other protection devices [19,29-33].

Furthermore, sensor selectivity might be achieved by additional PL lifetime characterization that can reveal the different PL quenching mechanisms. In summary, we have used a simple, green procedure to develop an optical sensor for silica and $\mathrm{ZnO}$ nanoparticles and GnP. We propose the current sensor as a practical solution for the fast detection of these nanomaterials, either in colloids or in powder form.

\section{Materials and Methods}

\subsection{Materials and Sample Preparation}

Brown sugar was purchased from the local supermarket (Italy). Polyvinyl alcohol (PVA, Mw 146,000-186,000) was purchased from Sigma Aldrich. Filter paper was purchased from Whatman (Grade 1). MilliQ water was used as a solvent. Silica NPs $(\sim 50 \mathrm{~nm})$ were donated by Hiq-Nano (Italy). $\mathrm{ZnO}$ nanoparticles $(20-30 \mathrm{~nm}$ ) were purchased from Alfa Aesar. Graphene nanoplatelets ( $\mathrm{GnP}$, thickness $6-8 \mathrm{~nm}$, width $\sim 5 \mu \mathrm{m}$ ) were purchased from Strem Chemicals.

Carbon dots were prepared following the procedure described in our previous work [34]. In short, equal amounts of brown sugar and water were heated in a furnace at $180{ }^{\circ} \mathrm{C}$ 
$\left(5^{\circ} \mathrm{C} / \mathrm{min}\right.$ ) for $48 \mathrm{~h}$, resulting in carbonization. The carbonized mass was dispersed in MilliQ water and filtered through a $0.2 \mu \mathrm{m}$ membrane. The filtered dispersion was freeze dried and re-dispersed in MilliQ water at a concentration of $2 \mathrm{mg} / \mathrm{mL}$.

PVA was mixed in water $(5 \% w / v)$ and placed on a hot plate at $90{ }^{\circ} \mathrm{C}$ under magnetic stirring until it was dissolved. Carbon dots aqueous dispersion $(2 \mathrm{mg} / \mathrm{mL})$ was mixed with PVA solution, at a concentration $10 \% w / w$. The final concentration of the composite solution was $1.6 \% w / v$.

\subsection{Functionalization of Paper Strips}

The paper sensors were prepared by dip coating. Whatman filter paper was cut into rectangular pieces $(2.0 \mathrm{~cm} \times 1.0 \mathrm{~cm})$ that were dipped for $10 \mathrm{~min}$ in $2 \mathrm{~mL}$ of the carbon dot/PVA composite solution $(10 \% w / w)$. Subsequently, the paper sensors were let to dry overnight at ambient conditions. For the sensing experiments, the paper sensors were dipped in aqueous dispersions containing different concentrations of silica NPs. After $30 \mathrm{~s}$, they were removed from the silica NP aqueous dispersion, left to dry in ambient conditions, and the changes of PL were studied using a fluorometer. Finally, a sweep test was performed, where the paper strip was swept over clean surfaces and surfaces contaminated with silica NPs. The change in emission was then observed under illumination with a UV-lamp (254 nm).

\subsection{Characterization}

Absorption curves of the dispersions were taken by a UV-visible spectrophotometer (CARY200 Scan, Varian, USA). Photoluminescence (PL) was measured by a fluorometer (FluoroMax, Horiba, Japan). In addition, detailed steady-state and lifetime PL measurements were carried out with an Edinburgh Instruments spectrofluorometer (model FLS920). For the PL spectra collection, the samples were excited with a Xenon lamp at $300 \mathrm{~nm}$, while a time-correlated single-photon-counting (TCSPC) unit coupled with a pulsed LED diode $(\lambda e x=300 \mathrm{~nm})$ was used for time-resolved PL measurements at the PL peak maximum using a repetition rate of $10 \mathrm{MHz}$. Liquid samples were measured in quartz cuvettes (Hellma Analytics ${ }^{\circledR}$, Germany) with a path length of $10 \mathrm{~mm}$, while paper samples were placed in a solid holder. All measurements were carried out using the same experimental parameters (slit size, repetition rate, etc.).

A UV-lamp (254 nm) was used to illuminate the fluorescence of both solution and paper specimens. Photographs were taken with a digital camera and analyzed by ImageJ software [35].

X-ray photoelectron spectroscopy (XPS) was performed using an electron spectrometer (Lab2, Specs, Germany) equipped with a monochromatic X-ray source (1486 eV) and a hemispherical energy analyzer (Phoibos, HSA3500, Specs, Germany). The applied voltage of the $\mathrm{Al} \mathrm{K} \alpha \mathrm{X}$-ray source was set at $13 \mathrm{kV}$ and the applied current at $8 \mathrm{~mA}$. The pressure in the analysis chamber was $\sim 1 \times 10^{-9}$ mbar. A large area lens mode was used for both wide and narrow scans. For the wide scan, the energy pass was $90 \mathrm{eV}$ and the energy step was $1 \mathrm{eV}$. For the narrow high-resolution scan, the energy pass was $30 \mathrm{eV}$ and the energy step was $0.1 \mathrm{eV}$. A flood gun was used to neutralize the surface charge, having an energy of $7 \mathrm{eV}$ and a filament current of 2.2 A. XPS samples were prepared by carbon dots deposited on $\mathrm{Cu}$ tape, and silica nanoparticles deposited on the carbon dots.

Imaging of the paper sensors and energy dispersive X-ray (EDX) analysis were carried out by a high-resolution scanning electron microscope (HR-SEM, JEOL JSM 7500FA, c Japan), equipped with a cold field emission gun (FEG), operating at a $5 \mathrm{kV}$ acceleration voltage.

\section{Results and Discussion}

The different steps, from the production of carbon dots to paper functionalization and PL quenching, are depicted in Scheme 1. 


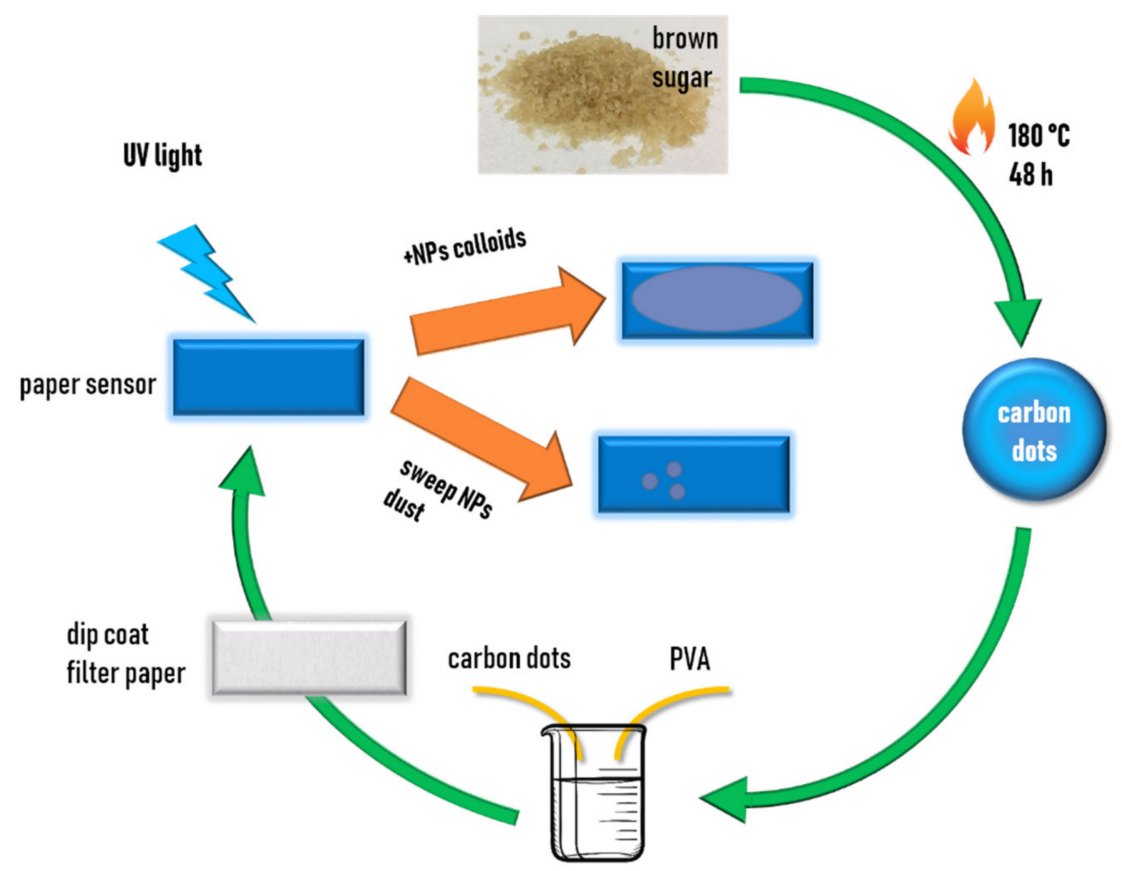

Scheme 1. Schematic illustration of the fabrication method of the carbon dots and consequently the functionalized paper strips. The PL emission of the functionalized paper strips is quenched when they are exposed either to colloids of the different nanomaterials, or by sweeping their dust.

Carbon dots were prepared by carbonization of brown sugar. A detailed characterization has been published previously by our group [34]: their diameter was measured to be ca. $4.12 \pm 0.54 \mathrm{~nm}$ and their emission spectrum was centered at $448 \mathrm{~nm}$ under an excitation of $300 \mathrm{~nm}$.

First, the carbon dot aqueous dispersion was mixed with the PVA aqueous solution $(10 \% w / w)$ and characterized optically by UV-vis absorption and fluorescence spectroscopies. Figure 1a shows the UV-vis absorption (black line) and PL emission spectra (red line) of the carbon dot/PVA composite aqueous solution. The absorption spectrum exhibits a peak at $275 \mathrm{~nm}$ and a weak shoulder at $\sim 350 \mathrm{~nm}$. The absorption peak is due to the $\pi-\pi^{*}$ transition of the aromatic sp2 domains of the $\mathrm{C}=\mathrm{C}$ bond, while the shoulder was assigned to the $\mathrm{n}-\pi^{*}$ of the $\mathrm{C}=\mathrm{O}$ bond of the carbon dots [17,36-38]. The PL emission peak is centered at $438 \mathrm{~nm}$, under $300 \mathrm{~nm}$ wavelength excitation. As shown in the inset of Figure 1a, pure PVA solution is colorless under UV light, while PVA solution containing carbon dots has a bright blue color, due to the fluorescence of the carbon dots. The PL spectrum of the carbon dot/PVA solution shows a small dependence on the excitation wavelength, both in peak position and amplitude (Figure S1a). The thermal treatment during fabrication leads to a high degree of carbonization and a consequent reduction of the oxygenated functional groups on the surface of the carbon dots, enhancing the PL originating from the sp2 conjugation at the core [39,40]. For this reason, the emission peak position is stable $(\sim 438 \mathrm{~nm})$ for excitation wavelengths below $340 \mathrm{~nm}$. Excitation with wavelengths above $340 \mathrm{~nm}$ enhances the PL originating from color centers different than the carbon core (such as carbon clusters or surface states), resulting in a red shift of the emission peak up to ca. $470 \mathrm{~nm}[15]$. 

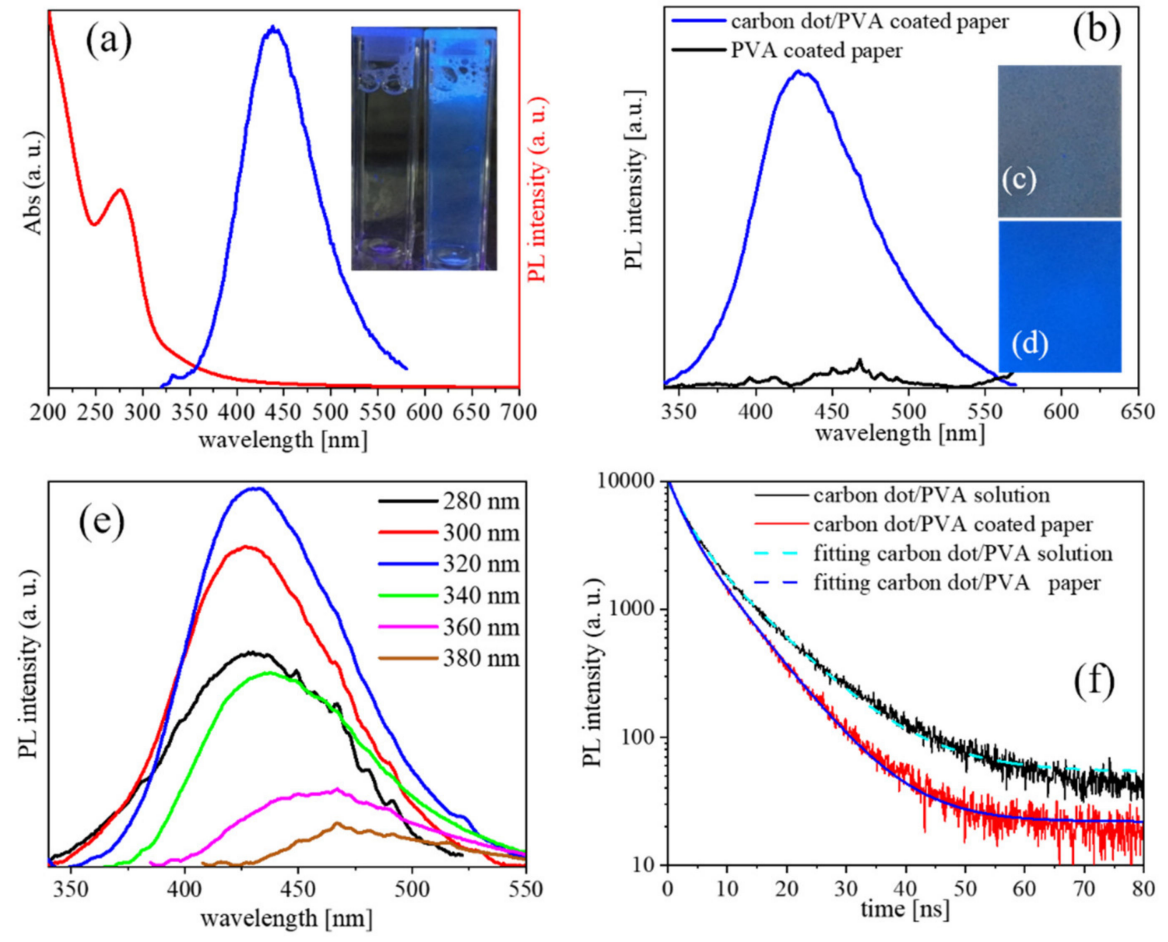

Figure 1. (a) Absorption and PL emission spectra of carbon dot/PVA water solution. Inset: photograph of PVA solution (left) and carbon dot/PVA solution (right) under a UV light (254 nm). (b) PL emission spectra for paper coated with pure PVA (red curve) and carbon dot/PVA (black curve). Inset: images of the (c) PVA coated paper and (d) paper functionalized with carbon dots/PVA, under a UV light $(254 \mathrm{~nm})$. The bright blue color of (d) comes from the carbon dot fluorescence. (e) PL emission as a function of excitation wavelength for the paper sensor, functionalized with carbon dots/PVA. (f) PL decay curves of PVA/carbon dot solution (black line) and a PVA/carbon dot coated paper sensor (red line).

Filter paper strips $(2.0 \mathrm{~cm} \times 1.0 \mathrm{~cm})$ were functionalized by immersion in $2 \mathrm{~mL}$ of carbon dot/PVA aqueous solution for $10 \mathrm{~min}$, and they were subsequently left to dry in ambient conditions. Control samples were also prepared by coating filter paper with pure PVA, following the same procedure. Figure $1 \mathrm{~b}$ shows the PL emission from a functionalized cellulosic paper and from a control sample, under $300 \mathrm{~nm}$ wavelength excitation. In comparison to the functionalized paper, the control sample has negligible PL. In the inset, images of the control sample (c) and functionalized paper (d) taken under UV light $(254 \mathrm{~nm})$ are displayed. The functionalized paper shows a bright blue fluorescence emission under a UV lamp. In comparison, the pure PVA coated paper exhibits a faded color of suppressed fluorescence. We can thus conclude that the observed PL of the complex system, comprising cellulosic paper, PVA, and carbon dots, comes only from the carbon dots. The PL dependence of the functionalized paper on the excitation wavelength, $\lambda$ ex, is shown in Figure 1e and follows the characteristics of the composite solution. Comparing the PL emissions from the composite solution and the functionalized paper, it becomes evident that at the same excitation wavelength $(300 \mathrm{~nm})$ there is a blueshift of the PL emission of the carbon dot/PVA solution ( $438 \mathrm{~nm}$ ) to the paper $(428 \mathrm{~nm}$ ) (SI, Figure S1b). This blueshift of the emission peak is due to the strong localization of the excitons in the presence of a solid matrix [36,41,42]. This is further supported by time-resolved photoluminescence measurements and the corresponding average lifetimes, as shown in Figure 1e.

The PL decay curves were fitted by a bi-exponential function (Figure 1e), i.e., with two decay components: a fast one ( $\tau_{1}$, ascribed to non-radiative exciton recombination) and a slower one ( $\tau_{2}$, ascribed to radiative exciton recombination) [24]. The calculated values for the average PL lifetime were $7.50 \pm 0.12 \mathrm{~ns}$ for the carbon dot/PVA solution and 
$6.13 \pm 0.03 \mathrm{~ns}$ for the carbon dot/PVA coated paper. In addition, the fitting parameters (Table S1, SI) show a decrease in $\tau_{1}$ in the case of carbon dot/PVA coated paper. Shorter decay times are expected to result from exciton localization, due to the presence of the polymer matrix $[43,44]$.

\subsection{Detection of Nanomaterials}

Carbon dot/PVA coated paper sensors were exposed to aqueous dispersions of silica $\mathrm{NPs}, \mathrm{ZnO}$ NPs, or GnP. In all cases, the PL spectrum of a pristine paper sensor is presented, before and after the paper sensor has been dipped in aqueous dispersion with concentrations $0.0001 \mathrm{mg} / \mathrm{mL}$ and $0.01 \mathrm{mg} / \mathrm{mL}$, for $30 \mathrm{~s}$, and subsequent water evaporation, in ambient conditions. In Figure $2 \mathrm{a}-\mathrm{c}$, the PL emission is shown to decrease after the paper sensor was exposed to all mentioned nanomaterials. For silica NPs and GnP, the PL emission intensity decreased more strongly with increasing nanomaterial concentration. On the other hand, the decrease of the PL emission intensity for $\mathrm{ZnO}$ did not depend on the concentration.
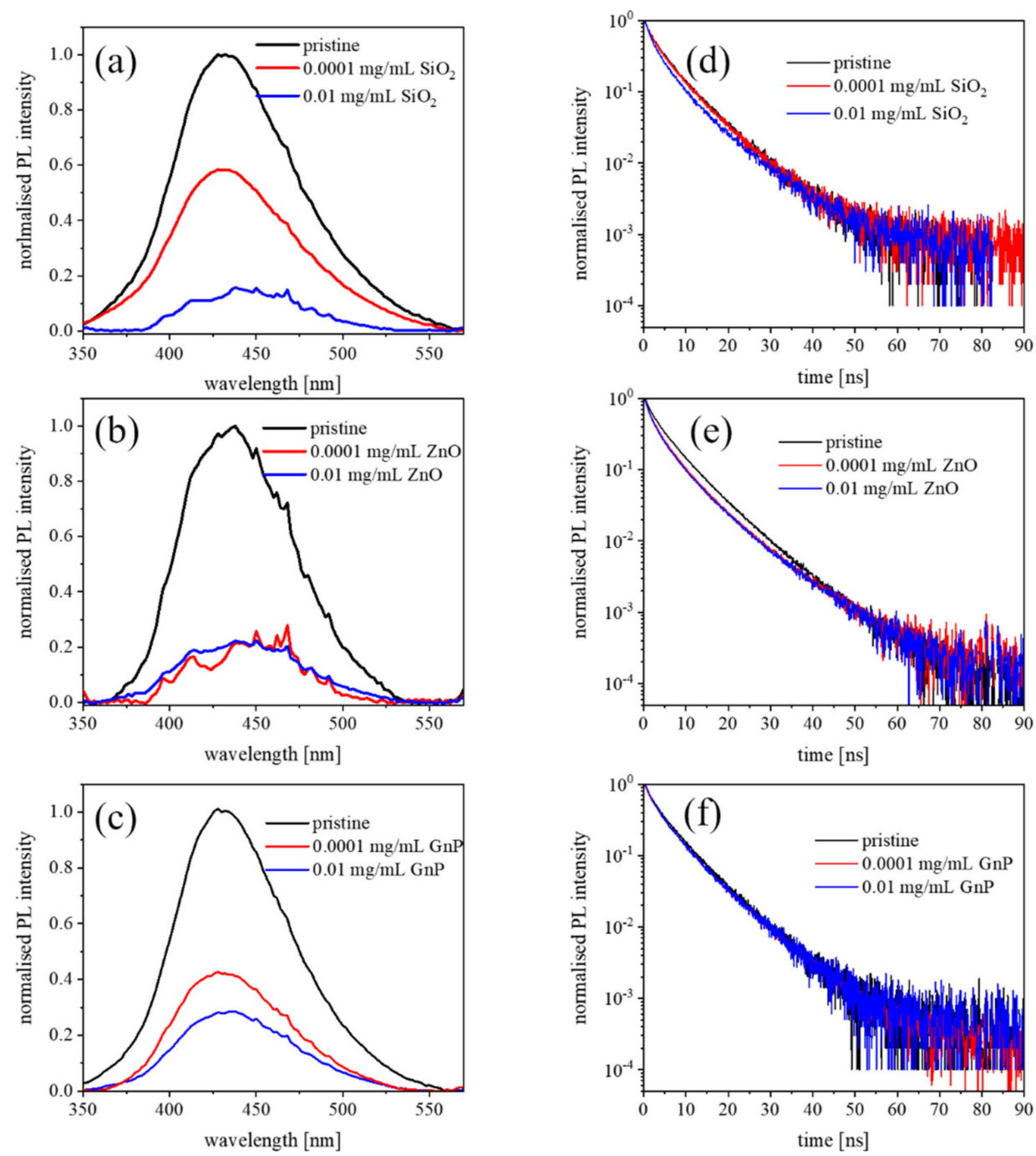

Figure 2. Normalized PL emission spectra of the paper sensor after it had been dipped in solutions containing different concentrations of (a) silica NPs, (b) ZnO NPs, and (c) GnP. Corresponding PL decay curves, showing the evolution of the PL emission of the paper sensor for (d) silica NPs, (e) $\mathrm{ZnO} N \mathrm{Ns}$, and (f) GnP. Two concentrations of aqueous dispersion of all nanomaterials were used: $0.0001 \mathrm{mg} / \mathrm{mL}$ and $0.01 \mathrm{mg} / \mathrm{mL}$ (fitting parameters are presented in SI, Tables S2 and S3). 
In order to better understand the observed PL quenching, we have investigated the emission lifetime of the different systems. The PL decay traces for the different nanomaterials are depicted in Figure $2 \mathrm{~d}-\mathrm{f}$. As we have already shown, the PL decay of the pristine paper sensor can be fitted with a biexponential function, resulting in an average lifetime of $6.13 \pm 0.03$ ns. The PL lifetime decreases when the functionalized paper is exposed to silica or ZnO NPs (Figure 2d,e). This decrease, together with the reduced emission intensity, (SI, Tables S2 and S3) indicates an increment of the non-radiative decay paths, when these nanomaterials are in contact with the paper sensor. On the other hand, PL lifetime measurements of the paper sensor exposed to GnP reveal static quenching of the carbon dot photoluminescence, as the PL decay trace remains unaltered. This is in accordance with Yu et al. [24], who observed static quenching of carbon dot photoluminescence by carbon nanotubes.

As depicted in Figure 2e, the PL lifetime of a paper sensor impregnated with ZnO NP does not depend on $\mathrm{ZnO}$ concentration. Furthermore, upon very careful inspection of the fitting, it was evident that these curves are better fit with three exponential components. The fitting parameters are shown in Table S2 (SI). This behavior can be explained by the photocatalytic properties of $\mathrm{ZnO}$ [45].

Upon UV irradiation (254 nm or $300 \mathrm{~nm}$ wavelength corresponding to $4.88 \mathrm{eV}$ and $4.1 \mathrm{eV}$, respectively), electron-hole pairs are generated in the $\mathrm{ZnO}$ lattice ( $\mathrm{ZnO}$ energy gap $\sim 3.37 \mathrm{eV}$ ). The PL quenching of the carbon dots can then be attributed to electron-hole recombination, due to non-radiative electron transfer from the carbon dots to $\mathrm{ZnO}$. As is well established in the literature, electron transfer takes place at the carbon dot-inorganic oxide interface, with the carbon dots injecting electrons into the inorganic oxide $[25,46,47]$. This is demonstrated in the PL decay traces of the paper sensor exposed to $\mathrm{ZnO}$ dispersions (SI, Table S2). The first, fastest component has been attributed to non-radiative electron transfer that results in the PL quenching [25].

The PL lifetime of the paper sensor impregnated with silica NPs (Figure 2d) can be fit using a biexponential function (SI, Table S3), resulting in slightly decreased average lifetimes (5.57 $\pm 0.10 \mathrm{~ns}$ for $0.01 \mathrm{mg} / \mathrm{mL}$ silica NPs). PL quenching in carbon dots with the above characteristics is typically explained by either electron or energy transfer between the fluorophore (i.e, the carbon dots) and the quencher (i.e., the silica NPs) [16]. The carbon dots used in the present study are hydrochromic, via hydrogen bonding and vibronic coupling with the surrounding water molecules $[34,48,49]$. Furthermore, silica NPs possess OH groups on their surface, typical of silanols that are known to engage in hydrogen bonding. When the silica NPs are in the vicinity of the carbon dots in the dried state (paper sensor), they are able to form hydrogen bonds with the carbonyls $(\mathrm{C}=\mathrm{O})$ [50] on the carbon dots, enabling non-radiative charge transfer from the carbon dots to the silica NPs. This scenario was verified by XPS measurements (SI, Figure S2). Pure silica NPs show one Si peak at 104.14 eV, while in the case of silica NPs deposited on carbon dots, two Si peaks appear at $104.13 \mathrm{eV}$ and $102.2 \mathrm{eV}$. Si peaks at these energies correspond to different atomic oxidation states, where lower energies correspond to lower oxidation states [51]. Hence, the presence of the new peak at $102.2 \mathrm{eV}$ signifies the presence of $\mathrm{Si}$ atoms with lower oxidation states, corroborating the proposed scheme of their interaction with the carbon dots.

Furthermore, control experiments were carried out by dipping a paper sensor for $30 \mathrm{~s}$ in pure water and measuring PL emission and decay. It was shown that the PL emission decrease is distinctly smaller than when the paper strips have come in contact with nanomaterials, while there are no PL lifetime changes (SI, Figure S3).

Taking into consideration the effect of water, the quenching seen in Figure $2 b$ for $0.0001 \mathrm{mg} / \mathrm{mL}$ silica NPs on the paper sensor might have been due to water and not due to silica. In order to verify this, we tested PL quenching and lifetime of the functionalized paper for different concentrations of silica NPs in water (Figure S3). In Figure 3a, the relative PL intensity quenches when the cellulose sensor is exposed to silica NP solutions is shown, with concentrations down to $2 \times 10^{-3} \mathrm{mg} / \mathrm{mL}$, while for lower silica concentrations no significant PL changes could be measured. In Figure S4a (SI) the relative PL is depicted against the $\log \mathrm{x}$-axis. 

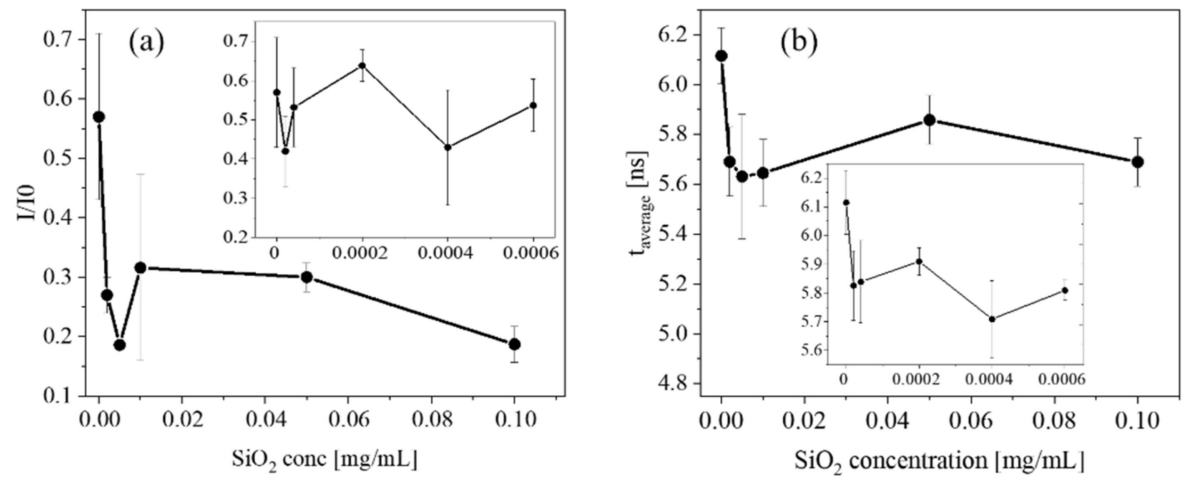

Figure 3. (a) Relative PL and (b) the corresponding average lifetime, with respect the different concentrations of silica aqueous dispersions. In the main panels, the silica concentration varies from $2 \times 10^{-3} \mathrm{mg} / \mathrm{mL}$ to $0.1 \mathrm{mg} / \mathrm{mL}$. In the insets, silica concentration varies from $2 \times 10^{-5} \mathrm{mg} / \mathrm{mL}$ to $6 \times 10^{-4} \mathrm{mg} / \mathrm{mL}$.

Furthermore, Figure 3b (and in SI, Figure S4b) depicts the corresponding measurements of the average lifetime of the paper sensors. Interestingly, PL lifetime becomes shorter after the exposure to silica for all silica concentrations, indicating dynamic quenching. Finally, revisiting the fitting parameters of the PL decay (SI, Table S3), we notice that even though the average lifetime of the sensors exposed to silica is shorter than the lifetime of the pristine sensor, $\tau_{1}$ and $\tau_{2}$ do not change significantly. However, what does change is the contribution of the faster decay (A1) that is increasing upon the addition of silica NPs, signifying non-radiative charge transfer from the carbon dots to the silica NPs $[17,24]$.

\subsection{Optical Detection under a UV Lamp}

Figure 4 depicts digital photographs of paper sensors, pristine and exposed to aqueous dispersions of silica, $\mathrm{ZnO}$ or GnP (concentration was $0.01 \mathrm{mg} / \mathrm{mL}$ ), taken under a UV lamp $(254 \mathrm{~nm})$. In order to facilitate the detection of the color change, the photographs underwent post-processing using ImageJ software. By splitting the RGB channels and applying an appropriate color filter to the blue channel, the stains of quenched PL can be distinguished more clearly. The original images are shown in Figure S5 (SI).

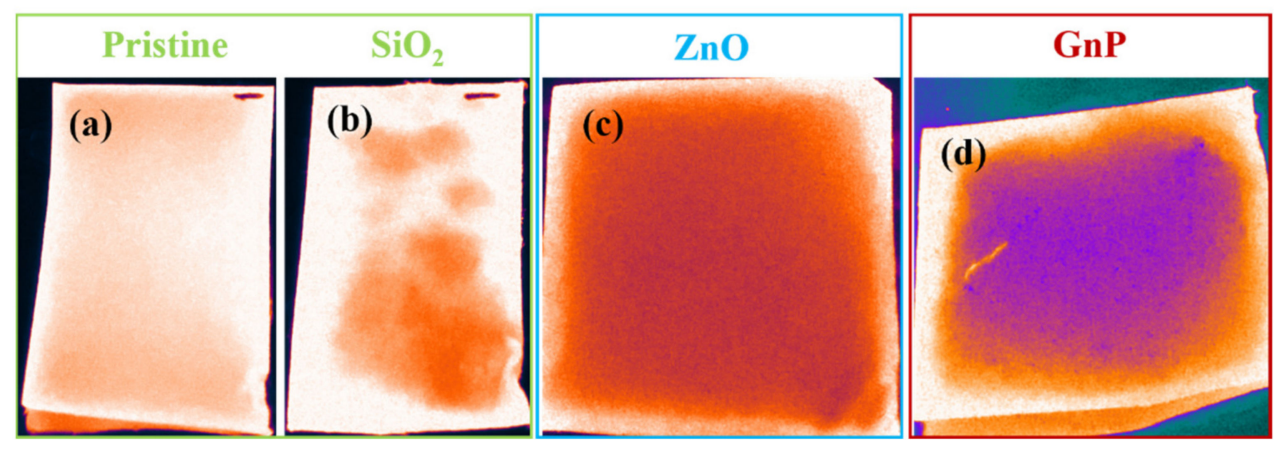

Figure 4. Processed images (by ImageJ) of the paper sensors (dimensions: $2.0 \times 1.0 \mathrm{~cm}^{2}$ for (a) and (b), and $1.0 \times 1.0 \mathrm{~cm}^{2}$ for $(\mathbf{c}, \mathbf{d})$, under a UV lamp $(254 \mathrm{~nm})$ : (a) carbon dot/PVA coated paper sensor, and of paper sensors exposed to an aqueous solutions $(0.01 \mathrm{mg} / \mathrm{mL})$ of $(\mathbf{b})$ silica NPs, (c) ZnO NPs, and (d) GnP.

The pristine paper sensor (Figure 4a) displays a light, homogeneous color, in contrast to the paper sensors exposed to silica (Figure $4 \mathrm{~b}$ ) that exhibit patches of darker shades that correspond to the quenched fluorescence. Exposure to ZnO NPs (Figure 4c) and GnP (Figure $4 \mathrm{~d}$ ) leads to a homogeneous quenching of the PL emission. The inhomogeneity of 
the quenched fluorescence in the case of interaction with silica NPs is understood in terms of the uneven diffusion of the silica NPs in the cellulose fibers.

We have, thus, demonstrated that a paper sensor comprised of carbon dots, and stabilized on cellulose fibers with PVA, can serve as a fluorescent sensor for the fast detection of silica, $\mathrm{ZnO}$ nanoparticles, or GnP in solution, as PL intensity quenching is observed under UV light. Furthermore, a detailed study of the PL lifetime allows distinguishing between oxide nanoparticles and $\mathrm{GnPs}$; therefore, providing selectivity to the sensor. Up to now, the selectivity of the paper sensor can be achieved only via PL lifetime measurements. Future work can be envisioned surface functionalization of the carbon dots to improve their selectivity.

\section{3. "Sweep Test" for the Detection of Powders}

In order to check the capability of our paper sensor to detect the powders of the above-mentioned nanomaterials, we have devised a "sweep test". During these tests, various amounts of the aforementioned nanopowders were placed on a clean microscope glass and the paper sensor was swept over, first, a clean glass surface and subsequently the contaminated surface, brushing the powder. After each sweep, the sensor was inspected under a UV lamp $(254 \mathrm{~nm})$. Figure 5a-c depict representative images of the pristine paper sensor, while Figure $5 \mathrm{~d}-\mathrm{f}$ depict the same sensors after sweeping over the lowest detectable amounts of silica, $\mathrm{ZnO}$, or $\mathrm{GnP}$ nanopowders. The images of the cellulose sensors under the UV lamp $(254 \mathrm{~nm})$ show that a simple sweeping of surfaces contaminated with silica, $\mathrm{ZnO}$ nanoparticles, or GnP leads to localized quenching in the PL of the cellulose sensor. The inspection of the paper sensors under the UV lamp indicated changes in the fluorescence due to the collection of the nanomaterials powder. Furthermore, we have performed sweep tests for increasing amounts of the nanopowders, shown in the SI, Figure S7.
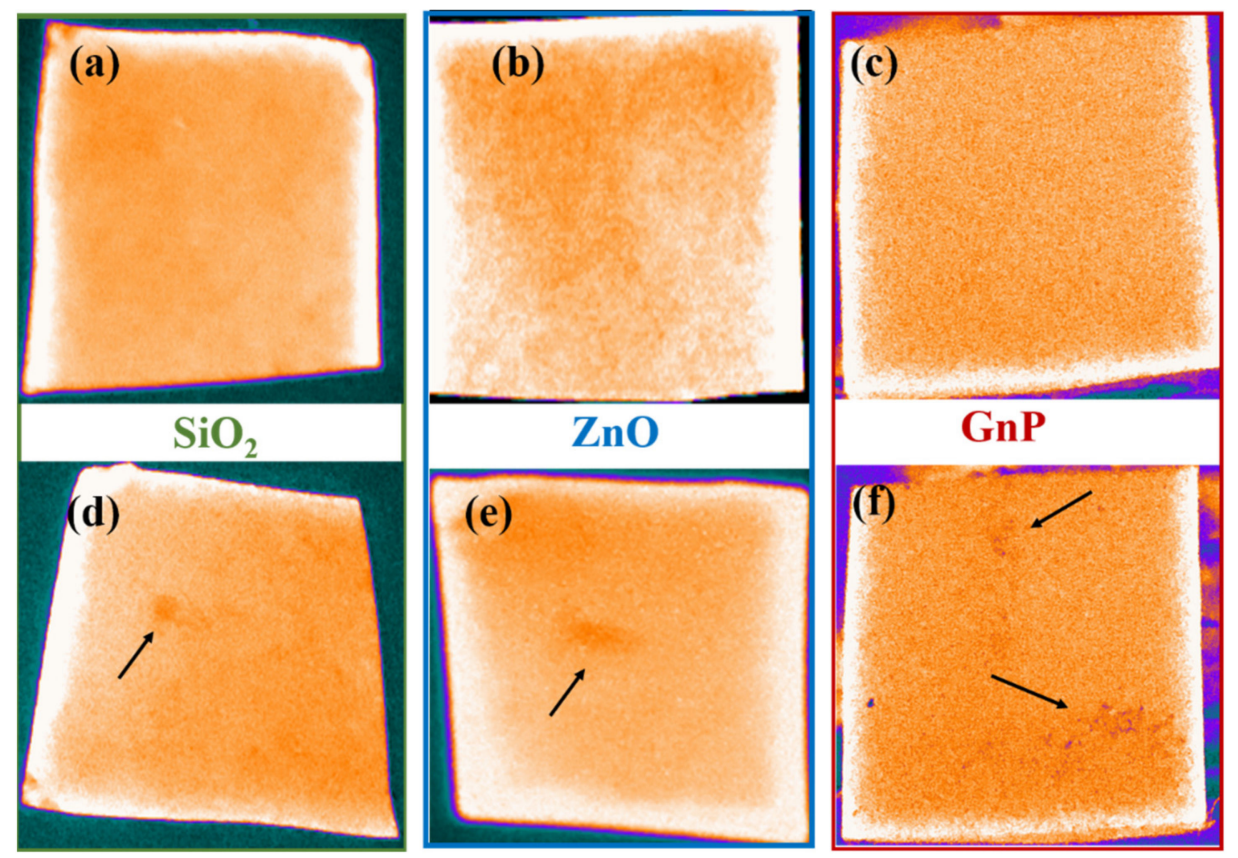

Figure 5. Processed digital images of pristine cellulose sensors after sweeping a clean surface (a-c), and the same sensors after sweeping the surfaces contaminated with the lowest detectable amounts of (d) silica NPs (0.2 mg), (e) ZnO NPs (0.002 mg), and (f) GnPs (0.001 mg), respectively. The digital images were captured under a UV lamp $(254 \mathrm{~nm}$ ) and were processed with ImageJ (the original digital photos are presented in SI, Figure S6). The size of the cellulosic paper was ca. $1.0 \mathrm{~cm} \times 1.0 \mathrm{~cm}$.

Designing the sweep tests, we have considered that common dust is always present, including on surfaces potentially contaminated with the above-mentioned nanomaterials. 
Therefore, we have performed the sweep test on a dusty surface (windowsill) and inspected the sample under the UV lamp. As shown in Figure S8 (SI) the dust did not affect the PL intensity of the cellulose sensor, thus excluding the possibility that the presence of dust would interfere with the signal.

The selectivity of the sensor during the sweep test requires further analysis, for example high resolution scanning electron microscopy and energy dispersive X-ray (EDX) analysis. In addition, this test cannot give quantitative information, and the quantities used were the minimum quantities detectable. However, the facile use of the proposed paper sensor renders the device ideal for the fast detection of nanomaterials, such as $\mathrm{SiO}_{2}$ and $\mathrm{ZnO}$ NPs or GnP on surfaces such as benches, lab scales, etc., especially in a single-material production line.

\section{Conclusions}

We have designed and fabricated a paper sensor for the detection of oxide nanoparticles and graphene nanoplatelets. The preparation of the sensor is facile and green, involving the stabilization of eco-friendly carbon dots on cellulosic paper using water-soluble PVA as binding agent. The carbon nanodots convey fluorescence properties to the paper strips when irradiated with UV light. The paper sensor is able to detect the presence of the nanomaterials, upon direct contact with either their solution or powder, via the PL intensity quenching of the carbon dots. The different PL quenching mechanisms, evident from lifetime measurements, convey selectivity to the sensor.

Paper sensors can prove a fast and reliable method of detecting the presence of nanomaterials in colloids or dust. Even though more sophisticated analytical techniques will be required to quantify the amount of the detected analytes, the fast detection delivered by the proposed sensor provides an easy solution for nanomaterial detection in diverse environments, such as liquid suspensions or contaminated surfaces. Other advantages of such sensors include their ease of fabrication, the fact that they are environmentally friendly, and that they are lightweight and low-cost. We believe that this new approach for silica detection will be useful for everyday inspection and will prompt the development of optical paper sensors for different applications.

\section{Patents}

Patent pending: Italian Patent Application n.102021000009509; title "SENSORE E METODO PER LA RILEVAZIONE DI NANOPRODOTTI".

Supplementary Materials: The following are available online at https:/ / www.mdpi.com/article / 10.3390/su132111896/s1, Figure S1: (a) PLspectra for different excitation wavelength, and (b) PL peak dependence on different excitation wavelength. Figure S2: XPS measurements of carbon dots and carbon dots in contact with silica NPs. Figure S3: The role of water in the PL quenching and PL lifetime in paper sensors. Figure S4: Relative PL intensity and lifetime vs different silica NP concentrations. Figure S5: Digital images of paper sensors exposed to aqueous solutions of NPs. Figure S6: Digital images of paper sensors after the sweep tests. Figure S7: Digital images of paper sensors after the sweep tests for different amounts of nanomaterials. Figure S8: Images of paper sensors after the sweep test of dust. Table S1: PL lifetimes and fitting parameters of carbon dot/PVA solution and paper sensor. Table S2: PL lifetimes and fitting parameters of paper sensors exposed to ZnO NPs. Table S3: PL lifetimes and fitting parameters of paper sensors exposed to GnP.

Author Contributions: Conceptualization, E.L.P. and A.A.; data curation, E.L.P.; methodology, E.L.P.; validation, E.L.P. and G.B.; formal analysis, E.L.P. and G.B.; investigation, E.L.P., G.B., A.S., B.M.-G. and R.C.; writing—original draft preparation, E.L.P.; writing—review and editing E.L.P., G.B., B.M.G., R.K. and A.A.; supervision, R.K. and A.A.; funding acquisition, A.A. All authors have read and agreed to the published version of the manuscript.

Funding: This research was part of the Project "Nano and Key enabling technologies within the innovation processes: risk and opportunities in occupational settings by prevention through design (NanoKey_EPTR0003))", funded by the Italian Workers' Compensation Authority (INAIL) and 
coordinated in cooperation between the INAIL Department of Occupational and Environmental Medicine Epidemiology and Hygiene, and the Italian Institute of Technology (IIT).

Institutional Review Board Statement: Not applicable.

Informed Consent Statement: Not applicable.

Data Availability Statement: Data available upon request.

Acknowledgments: HiQ Nano s.l.r. is acknowledged for providing the silica nanoparticles in the frame of NanoKey project (INAIL).

Conflicts of Interest: The authors declare no conflict of interest. The funders had no role in the design of the study; in the collection, analyses, or interpretation of data; in the writing of the manuscript, or in the decision to publish the results.

\section{References}

1. Fytianos, G.; Rahdar, A.; Kyzas, G.Z. Nanomaterials in Cosmetics: Recent Updates. Nanomaterials 2020, 10, 979. [CrossRef]

2. Singh, T.; Shukla, S.; Kumar, P.; Wahla, V.; Bajpai, V.K.; Rather, I.A. Application of Nanotechnology in Food Science: Perception and Overview. Front. Microbiol. 2017, 8, 1501. [CrossRef]

3. Mitchell, M.J.; Billingsley, M.M.; Haley, R.M.; Wechsler, M.E.; Peppas, N.A.; Langer, R. Engineering precision nanoparticles for drug delivery. Nat. Rev. Drug Discovery 2021, 20, 101-124. [CrossRef] [PubMed]

4. Zhang, Y.; Nayak, T.R.; Hong, H.; Cai, W. Biomedical applications of zinc oxide nanomaterials. Curr. Mol. Med. 2013, 13, 1633-1645. [CrossRef] [PubMed]

5. Astruc, D. Introduction: Nanoparticles in Catalysis. Chem. Rev. 2020, 120, 461-463. [CrossRef]

6. Kang, K.; Cho, Y.; Yu, K.J. Novel Nano-Materials and Nano-Fabrication Techniques for Flexible Electronic Systems. Micromachines 2018, 9, 263. [CrossRef] [PubMed]

7. Keller, A.A.; McFerran, S.; Lazareva, A.; Suh, S. Global life cycle releases of engineered nanomaterials. J. Nanopart. Res. 2013, 15, 1692. [CrossRef]

8. Guinée, J.B.; Heijungs, R.; Vijver, M.G.; Peijnenburg, W.J.G.M. Setting the stage for debating the roles of risk assessment and life-cycle assessment of engineered nanomaterials. Nat. Nanotechnol. 2017, 12, 727-733. [CrossRef] [PubMed]

9. Schulte, P.A.; Geraci, C.L.; Murashov, V.; Kuempel, E.D.; Zumwalde, R.D.; Castranova, V.; Hoover, M.D.; Hodson, L.; Martinez, K.F. Occupational safety and health criteria for responsible development of nanotechnology. J. Nanopart. Res. Interdiscip. Forum Nanoscale Sci. Technol. 2014, 16, 2153. [CrossRef] [PubMed]

10. Yang, X.; Liu, X.; Zhang, A.; Lu, D.; Li, G.; Zhang, Q.; Liu, Q.; Jiang, G. Distinguishing the sources of silica nanoparticles by dual isotopic fingerprinting and machine learning. Nat. Commun. 2019, 10, 1620. [CrossRef]

11. Tombolini, F.; Boccuni, F.; Ferrante, R.; Natale, C.; Marasco, L.; Mantero, E.; Del Rio Castillo, A.E.; Leoncino, L.; Pellegrini, V.; Sabella, S.; et al. An integrated and multi-technique approach to characterize airborne graphene flakes in the workplace during production phases. Nanoscale 2021, 13, 3841-3852. [CrossRef]

12. Aureli, F.; D'Amato, M.; Raggi, A.; Cubadda, F. Quantitative characterization of silica nanoparticles by asymmetric flow field flow fractionation coupled with online multiangle light scattering and ICP-MS/MS detection. J. Anal. At. Spectrom. 2015, 30, 1266-1273. [CrossRef]

13. Montaño, M.D.; Majestic, B.J.; Jämting, Å.K.; Westerhoff, P.; Ranville, J.F. Methods for the Detection and Characterization of Silica Colloids by Microsecond spICP-MS. Anal. Chem. 2016, 88, 4733-4741. [CrossRef]

14. Schmid, S.; Kurek, M.; Adolphsen, J.Q.; Boisen, A. Real-time single airborne nanoparticle detection with nanomechanical resonant filter-fiber. Sci. Rep. 2013, 3, 1288. [CrossRef]

15. Song, Y.; Zhu, S.; Xiang, S.; Zhao, X.; Zhang, J.; Zhang, H.; Fu, Y.; Yang, B. Investigation into the fluorescence quenching behaviors and applications of carbon dots. Nanoscale 2014, 6, 4676-4682. [CrossRef] [PubMed]

16. Zu, F.; Yan, F.; Bai, Z.; Xu, J.; Wang, Y.; Huang, Y.; Zhou, X. The quenching of the fluorescence of carbon dots: A review on mechanisms and applications. Microchim. Acta 2017, 184, 1899-1914. [CrossRef]

17. Das, R.; Rajender, G.; Giri, P.K. Anomalous fluorescence enhancement and fluorescence quenching of graphene quantum dots by single walled carbon nanotubes. Phys. Chem. Chem. Phys. 2018, 20, 4527-4537. [CrossRef] [PubMed]

18. Mintz, K.J.; Guerrero, B.; Leblanc, R.M. Photoinduced Electron Transfer in Carbon Dots with Long-Wavelength Photoluminescence. J. Phys. Chem. C 2018, 122, 29507-29515. [CrossRef]

19. Kim, Y.; Jang, G.; Lee, T.S. New Fluorescent Metal-Ion Detection Using a Paper-Based Sensor Strip Containing Tethered Rhodamine Carbon Nanodots. ACS Appl. Mater. Interfaces 2015, 7, 15649-15657. [CrossRef]

20. Liu, J.; Chen, Y.; Wang, W.; Feng, J.; Liang, M.; Ma, S.; Chen, X. "Switch-On" Fluorescent Sensing of Ascorbic Acid in Food Samples Based on Carbon Quantum Dots-MnO2 Probe. J. Agric. Food Chem. 2016, 64, 371-380. [CrossRef] [PubMed]

21. Abbas, M.W.; Soomro, R.A.; Kalwar, N.H.; Zahoor, M.; Avci, A.; Pehlivan, E.; Hallam, K.R.; Willander, M. Carbon quantum dot coated Fe3O4 hybrid composites for sensitive electrochemical detection of uric acid. Microchem. J. 2019, 146, 517-524. [CrossRef] 
22. Zhu, H.; Wang, E.; Li, J.; Wang, J. L-tyrosine methyl ester-stabilized carbon dots as fluorescent probes for the assays of biothiols. Anal. Chim. Acta 2018, 1006, 83-89. [CrossRef]

23. Pooja, D.; Saini, S.; Thakur, A.; Kumar, B.; Tyagi, S.; Nayak, M.K. A “Turn-On” thiol functionalized fluorescent carbon quantum dot based chemosensory system for arsenite detection. J. Hazard. Mater. 2017, 328, 117-126. [CrossRef]

24. Yu, P.; Wen, X.; Toh, Y.-R.; Lee, Y.-C.; Huang, K.-Y.; Huang, S.; Shrestha, S.; Conibeer, G.; Tang, J. Efficient electron transfer in carbon nanodot-graphene oxide nanocomposites. J. Mater. Chem. C 2014, 2, 2894-2901. [CrossRef]

25. Barman, M.K.; Mitra, P.; Bera, R.; Das, S.; Pramanik, A.; Parta, A. An efficient charge separation and photocurrent generation in the carbon dot-zinc oxide nanoparticle composite. Nanoscale 2017, 9, 6791-6799. [CrossRef] [PubMed]

26. Essner, J.B.; Baker, G.A. The emerging roles of carbon dots in solar photovoltaics: A critical review. Environ. Sci. Nano 2017, 4, 1216-1263. [CrossRef]

27. Algadi, H.; Mahata, C.; Woo, J.; Lee, M.; Kim, M.; Lee, T. Enhanced Photoresponsivity of All-Inorganic (CsPbBr3) Perovskite Nanosheets Photodetector with Carbon Nanodots (CDs). Electronics 2019, 8, 678. [CrossRef]

28. Algadi, H.; Umar, A.; Albargi, H.; Alsuwian, T.; Baskoutas, S. Carbon Nanodots as a Potential Transport Layer for Boosting Performance of All-Inorganic Perovskite Nanocrystals-Based Photodetector. Crystals 2021, 11, 717. [CrossRef]

29. Li, M.; Li, X.; Xiao, H.-N.; James, T.D. Fluorescence Sensing with Cellulose-Based Materials. Chem. Open 2017, 6, 685-696. [CrossRef] [PubMed]

30. Chen, D.; Chen, P.; Zong, L.; Sun, Y.; Liu, G.; Yu, X.; Qin, J. Colorimetric and fluorescent probes for real-time naked eye sensing of copper ion in solution and on paper substrate. R. Soc. Open Sci. 2017, 4, 171161. [CrossRef] [PubMed]

31. Sarwar, M.; Leichner, J.; Naja, G.M.; Li, C.-Z. Smart-phone, paper-based fluorescent sensor for ultra-low inorganic phosphate detection in environmental samples. Microsyst. Nanoeng. 2019, 5, 56. [CrossRef] [PubMed]

32. Wang, H.; Vagin, S.I.; Rieger, B.; Meldrum, A. An Ultrasensitive Fluorescent Paper-Based CO2 Sensor. ACS Appl. Mater. Interfaces 2020, 12, 20507-20513. [CrossRef]

33. Maity, A.; Mitra, S.; Das, C.; Siraj, S.; Raychaudhuri, A.K.; Ghosh, B. Universal sensing of ammonia gas by family of lead halide perovskites based on paper sensors: Experiment and molecular dynamics. Mater. Res. Bull. 2021, 136, 111142. [CrossRef]

34. Senthamizhan, A.; Fragouli, D.; Balusamy, B.; Patil, B.; Palei, M.; Sabella, S.; Uyar, T.; Athanassiou, A. Hydrochromic carbon dots as smart sensors for water sensing in organic solvents. Nanoscale Adv. 2019, 1, 4258-4267. [CrossRef]

35. Rasband, W.S. ImageJ U.S. National Institutes of Health: Bethesda, MD, USA. Available online: http://imagej.nih.gov/ij (accessed on 10 September 2021).

36. Wang, W.; Lai, H.; Cheng, Z.; Kang, H.; Wang, Y.; Zhang, H.; Wang, J.; Liu, Y. Water-induced poly(vinyl alcohol)/carbon quantum dot nanocomposites with tunable shape recovery performance and fluorescence. J. Mater. Chem. B 2018, 6, 7444-7450. [CrossRef]

37. Yang, X.; Zhuo, Y.; Zhu, S.; Luo, Y.; Feng, Y.; Dou, Y. Novel and green synthesis of high-fluorescent carbon dots originated from honey for sensing and imaging. Biosens. Bioelectron. 2014, 60, 292-298. [CrossRef] [PubMed]

38. Pan, D.; Zhang, J.; Li, Z.; Wu, M. Hydrothermal Route for Cutting Graphene Sheets into Blue-Luminescent Graphene Quantum Dots. Adv. Mater. 2010, 22, 734-738. [CrossRef] [PubMed]

39. Eda, G.; Lin, Y.-Y.; Mattevi, C.; Yamaguchi, H.; Chen, H.-A.; Chen, I.-S.; Chen, C.-W.; Chhowalla, M. Blue Photoluminescence from Chemically Derived Graphene Oxide. Adv. Mater. 2010, 22, 505-509. [CrossRef] [PubMed]

40. Ehrat, F.; Bhattacharyya, S.; Schneider, J.; Löf, A.; Wyrwich, R.; Rogach, A.L.; Stolarczyk, J.K.; Urban, A.S.; Feldmann, J. Tracking the Source of Carbon Dot Photoluminescence: Aromatic Domains versus Molecular Fluorophores. Nano Lett. 2017, 17, 7710-7716. [CrossRef]

41. Yang, P.; Zhou, L.; Zhang, S.; Wan, N.; Pan, W.; Shen, W. Facile synthesis and photoluminescence mechanism of graphene quantum dots. J. Appl. Phys. 2014, 116, 244306. [CrossRef]

42. Guha, S.; Rice, J.D.; Yau, Y.T.; Martin, C.M.; Chandrasekhar, M.; Chandrasekhar, H.R.; Guentner, R.; Scanduicci de Freitas, P.; Scherf, U. Temperature-dependent photoluminescence of organic semiconductors with varying backbone conformation. Phys. Rev. B 2003, 67, 125204. [CrossRef]

43. Rose, A.; Tovar, J.D.; Yamaguchi, S.; Nesterov, E.E.; Zhu, Z.; Swager, T.M. Energy migration in conjugated polymers: The role of molecular structure. Philos. Trans. R. Soc. A 2007, 365, 1589-1606. [CrossRef] [PubMed]

44. Velayudham, S.; Lee, C.H.; Xie, M.; Blair, D.; Bauman, N.; Yap, Y.K.; Green, S.A.; Liu, H. Noncovalent Functionalization of Boron Nitride Nanotubes with Poly(p-phenylene-ethynylene)s and Polythiophene. ACS Appl. Mater. Interfaces 2010, 2, 104-110. [CrossRef] [PubMed]

45. Papadopoulou, E.L.; Zorba, V.; Pagkozidis, A.; Barberoglou, M.; Stratakis, E.; Fotakis, C. Reversible wettability of ZnO nanostructured thin films prepared by pulsed laser deposition. Thin Solid Films 2009, 518, 1267-1270. [CrossRef]

46. Li, H.; Kang, Z.; Liu, Y.; Lee, S.-T. Carbon nanodots: Synthesis, properties and applications. J. Mater. Chem. 2012, 22, $24230-24253$. [CrossRef]

47. Long, R. Understanding the Electronic Structures of Graphene Quantum Dot Physisorption and Chemisorption onto the TiO2 (110) Surface: A First-Principles Calculation. ChemPhysChem 2013, 14, 579-582. [CrossRef] [PubMed]

48. Mukherjee, S.; Prasad, E.; Chadha, A. H-Bonding controls the emission properties of functionalized carbon nano-dots. Phys. Chem. Chem. Phys. 2017, 19, 7288-7296. [CrossRef]

49. Giusti, L.A.; Marini, V.G.; Machado, V.G. Solvatochromic behavior of 1-(p-dimethylaminophenyl)-2-nitroethylene in 24 binary solvent mixtures composed of amides and hydroxylic solvents. J. Mol. Liq. 2009, 150, 9-15. [CrossRef] 
50. Liao, H.-Y.; Chu, S.-Y. Hydrogen bond acceptor capability of carbonyl $\pi$-electrons—case study of the hydrogen-bonded urea dimer. New J. Chem. 2003, 27, 421-424. [CrossRef]

51. Wang, T.-H.; Gole, J.L.; White, M.G.; Watkins, C.; Street, S.C.; Fang, Z.; Dixon, D.A. The surprising oxidation state of fumed silica and the nature of water binding to silicon oxides and hydroxides. Chem. Phys. Lett. 2011, 501, 159-165. [CrossRef] 